\title{
Cantharidin alters the expression of genes associated with the NKG2D-associated immune response in TSGH-8301 human bladder carcinoma cells
}

\author{
JEHN-HWA KUO ${ }^{1,2}$, AN-CHENG HUANG ${ }^{3}$, JEN-JYH LIN ${ }^{4}$, KUANG-CHI LAI ${ }^{5,6}$, RICK SAI-CHUEN WU ${ }^{5,7}$, \\ JIUN-LONG YANG ${ }^{8}$, BIN-CHUAN JI ${ }^{9}$, MEI-DUE YANG ${ }^{10}$, YUNG-LIN CHU ${ }^{11}$ and JING-GUNG CHUNG ${ }^{12,13}$
}

${ }^{1}$ Special Class of Healthcare, Industry Management, Central Taiwan University of Science and Technology, Taichung 40601; ${ }^{2}$ Department of Urology, Jen-Ai Hospital, Taichung 412; ${ }^{3}$ Department of Nursing, St. Mary's Junior College of Medicine, Nursing and Management, Yilan 26644; ${ }^{4}$ Division of Cardiology, China Medical University Hospital; ${ }^{5}$ School of Medicine, China Medical University, Taichung 404; ${ }^{6}$ Department of Surgery, China Medical University Beigang Hospital, Yunlin 651;

${ }^{7}$ Department of Anesthesiology, China Medical University Hospital; ${ }^{8}$ Department of Chinese Pharmaceutical Sciences and Chinese Medicine Resources, China Medical University, Taichung 404; ${ }^{9}$ Division of Chest Medicine, Department of

Internal Medicine, Changhua Christian Hospital, Changhua 500; ${ }^{10}$ Department of Surgery, China Medical

University Hospital, Taichung 404; ${ }^{11}$ International Master's Degree Program in Food Science,

Department of Food Science, International College, National Pingtung University of Science and Technology,

Pingtung 91201; ${ }^{12}$ Department of Biological Science and Technology, China Medical University,

Taichung 404; ${ }^{13}$ Department of Biotechnology, Asia University, Taichung 413, Taiwan, R.O.C.

Received March 2, 2016; Accepted February 3, 2017

DOI: $10.3892 / \mathrm{ol} .2017 .6168$

\begin{abstract}
Cantharidin (CTD) is a natural toxin in beetles of the Mylabris genus (blister beetle), which has been revealed to induce cell death in various types of human cancer cells. However, to the best of our knowledge, no previous studies have investigated the effect of CTD on the expression of genes and their associated signaling pathways in human bladder carcinoma cells. In the present study, CTD-induced cell morphological changes and apoptosis were observed using phase-contrast microscopy and the terminal deoxynucleotidyl transferase dUTP nick end labeling assay, respectively, in TSGH-8301 human bladder carcinoma cells. In addition, a complementary DNA microarray analysis demonstrated that CTD treatment led to a $>2$-fold upregulation of 269 genes. For example, the DNA damage-associated gene DNA-damage-inducible transcript 3 had a 4.75-fold upregulation. Furthermore, another 286 genes
\end{abstract}

Correspondence to: Professor Jing-Gung Chung, Department of Biological Science and Technology, China Medical University, 91 Hsueh-Shih Road, Taichung 404, Taiwan, R.O.C.

E-mail: jgchung@mail.cmu.edu.tw

Mr. Yung-Lin Chu, International Master's Degree Program in Food Science, Department of Food Science, International College, National Pingtung University of Science and Technology, 1 Shuefu Road, Neipu, Pingtung 91201, Taiwan, R.O.C.

E-mail: pig9104412003@hotmail.com

Key words: cantharidin, TSGH-8301 cells, apoptosis, in vitro were $>2$-fold downregulated in response to CTD treatment. Matrix-remodeling associated 5, which is associated with cell migration and invasion, was downregulated 7.98-fold.

\section{Introduction}

Cancer has long been recognized as a major causes of mortality in humans. Bladder cancer, a heterogeneous neoplasm, is either a low-grade tumor located in the superficial mucosa $(80 \%$ of cases) or a muscle-invasive carcinoma (20\% of cases) (1). Urothelial carcinoma is the most common type of bladder cancer and is a major cause of morbidity and mortality (2). In Western populations, bladder cancer represents the fourth most common malignancy affecting males $(3,4)$ and ranks thirteenth in terms of cancer-associated mortality worldwide $(5,6)$. The majority ( $>90 \%)$ of bladder tumors are of epithelial origin and arise from the bladder urothelium (7). The 2014 report from the Ministry of Health and Welfare of Taiwan indicated that bladder cancer was one of the most common types of cancer in Taiwan in 2006, with 1,985 new cases and 681 mortalities (8). Currently, the majority of treatments for superficial bladder cancer are derived from natural products. The aim of this treatment is to reduce tumor recurrence and prevent tumor progression.

Cantharidin (CTD), a natural toxin, is secreted by beetles of the Mylabris genus (blister beetle) and has been used as a traditional drug to treat Molluscum contagiosum viral infections and cancer in China and Vietnam $(9,10)$. For treating superficial bladder cancer, the correct dosage of CTD is important; an overdose of CTD may lead to mortality $(11,12)$. A number of studies have demonstrated that CTD induces cytotoxic effects 
on numerous human cancer cell lines. CTD was demonstrated to repress cancer cell growth through cell cycle arrest and the induction of apoptosis in cancer cells, including pancreatic cancer (13-15), leukemia U937 (16), human HepG2 (17), human colon cancer colo205 (18), human lung cancer A549 (19) and human bladder cancer (20) cells, in addition hepatocellular carcinoma in vivo (21). It has been reported that tamoxifen represses the phosphorylation of protein kinase $\mathrm{C}(\mathrm{PKC})$ and amplifies the anticancer effect induced by CTD (22). Previous studies have revealed a CTD-induced cytotoxic effect in melanoma A375.S (23), lung cancer NCI-H460 (24) and bladder cancer TSGH-8301 (25) cells.

Cancer arises from alterations in the structure, expression and function of tumor suppressor genes (26). A number of genetic mutations have been identified as biomarkers for the diagnosis and treatment of certain types of human cancer, including glioblastoma multiforme, but intratumoral heterogeneity presents challenges for personalized treatment strategies (27). Furthermore, genetic mutations in oncogenes and tumor suppressors have been identified in numerous types of cancer cells $(28,29)$. It has been determined, through constructing a protein-protein interaction network of differentially expressed genes and co-expressed genes, that $\mathrm{G}_{2} / \mathrm{M}$ phase-specific cyclin B1 and $\mathrm{H} 2 \mathrm{~A}$ histone family member $\mathrm{Z}$ are significantly associated with bladder cancer (30). A previous study suggested that fibroblast growth factor receptor 2 gene mutations in bladder cancer may only serve a minor role in bladder carcinogenesis (31). Another previous study demonstrated that CTD alters gene expression in human lung cancer NCI-H460 cells in vitro (32). It has also been hypothesized that CTD alters the gene expression of bladder cancer cells; however, to the best of our knowledge this has not yet been tested. In the present study, the effects of CTD treatment on NKG2D-associated immune response in TSGH-8301 human bladder carcinoma cells were investigated, including its effects on gene expression.

\section{Materials and methods}

Chemicals and reagents. CTD, propidium iodide, and dimethyl sulfoxide (DMSO) were purchased from Sigma-Aldrich (Merck KGaA, Darmstadt, Germany). All organic solvents used were of high performance liquid chromatography grade. RPMI-1640 medium, fetal bovine serum (FBS) and penicillin-streptomycin were obtained from Gibco (Thermo Fisher Scientific, Inc., Waltham, MA, USA). Tissue culture plastic wares were obtained from TPP Techno Plastic Products AG (Trasadingen, Switzerland). The ApoBrdU DNA Fragmentation Assay kit [terminal deoxynucleotidyl transferase dUTP nick end labeling (TUNEL)] was obtained from BioVision, Inc. (Milpitas, CA, USA). CTD was dissolved in DMSO and stored at $-20^{\circ} \mathrm{C}$ prior to use.

Human bladder cancer cell culture. TSGH-8301 human bladder carcinoma cells were purchased from the Food Industry Research and Development Institute (Hsinchu, Taiwan). Cells were cultured in T75 tissue culture flasks with RPMI-1640 medium supplemented with 10\% FBS and $1 \%$ penicillin-streptomycin $(100 \mathrm{U} / \mathrm{ml}$ penicillin and $100 \mu \mathrm{g} / \mathrm{ml}$
Table I. Number of genes that were upregulated or downregulated in TSGH-8301 cells following treatment with $7.5 \mu \mathrm{M}$ CTD compared with untreated control cells.

\begin{tabular}{lcc} 
A, Upregulated genes & & \\
\hline Fold change & Number of genes & Total \\
\hline$\geq 5$ and $<10$ & 7 & 269 \\
$\geq 4$ and $<5$ & 12 & \\
$\geq 3$ and $<4$ & 19 & \\
$\geq 2$ and $<3$ & 231 & \\
\hline
\end{tabular}

B, Downregulated genes

\begin{tabular}{lcc}
\hline Fold change & Number of genes & Total \\
\hline$>-3$ and $\leq-2$ & 233 & 286 \\
$>-4$ and $\leq-3$ & 34 & \\
$>-5$ and $\leq-4$ & 11 & \\
$>-10$ and $\leq-5$ & 8 &
\end{tabular}

streptomycin). Cell cultures were maintained in a humidified incubator at $37^{\circ} \mathrm{C}$ with $5 \% \mathrm{CO}_{2}$.

Cell morphology assay. Cell morphology was examined as described previously (25). Briefly, TSGH-8301 cells $\left(1 \times 10^{5}\right.$ cells/well) were trypsinized, seeded into a 12 -well plate with RPMI-1640 medium and cultured for $24 \mathrm{~h}$. The culture medium was then replaced with fresh medium containing CTD $(7.5 \mu \mathrm{M})$ and the plates were incubated for 12,24 and $48 \mathrm{~h}$ at $37^{\circ} \mathrm{C}$. TSGH-8301 cell morphology was subsequently examined using an Olympus phase-contrast microscope (Olympus Corporation, Tokyo, Japan).

TUNEL assay for cell apoptosis. The TUNEL assay was performed with the ApoBrdU DNA Fragmentation Assay kit according to the manufacturer's protocol (33). TSGH-8301 cells were seeded at a density of $1 \times 10^{5}$ cells/well onto coverslips, cultured with $7.5 \mu \mathrm{M}$ CTD for $48 \mathrm{~h}$ and then fixed with $4 \%$ formaldehyde in PBS for $15 \mathrm{~min}$, permeabilized with $0.1 \%$ (v/v) Triton X-100 for $1 \mathrm{~h}$ and washed with PBS. TUNEL staining solution was added to the coverslips to bind the fluorescein-dUTP to the DNA break terminals. TUNEL-positive cells were examined and images captured using a Leica TCS SP2 confocal microscope (Leica Microsystems GmBH, Wetzlar, Germany), using an excitation wavelength of 488-623 nm and a detection wavelength of 488-520 $\mathrm{nm}$.

Complementary (c)DNA microarray assay. TSGH-8301 cells were seeded into a $10 \mathrm{~cm}$ dish at a density of $1.5 \times 10^{6} \mathrm{cells} / \mathrm{dish}$ with RPMI-1640 medium and cultured for $24 \mathrm{~h}$. Cells were treated with $7.5 \mu \mathrm{M}$ CTD for $48 \mathrm{~h}$ and then collected and washed twice with PBS. Total RNA from the untreated control and CTD-treated groups were extracted using a Qiagen RNeasy Mini kit according to the manufacturer's protocol (Qiagen, Inc., Valencia, CA, USA). RNA concentrations were 
Table II. Representative genes that were upregulated or downregulated in response to CTD treatment in TSGH-8301 cells.

\begin{tabular}{|c|c|c|c|}
\hline Probe set ID & Gene symbol & Fold change & Gene description \\
\hline 7998927 & TRNAP24P & 6.7 & Transfer RNA proline 24 (anticodon AGG) pseudogene \\
\hline 7903530 & FNDC7 & 6.59 & Fibronectin type III domain containing 7 \\
\hline 8114572 & HBEGF & 6.15 & Heparin-binding EGF-like growth factor \\
\hline 7973433 & DHRS2 & 6.08 & Dehydrogenase/reductase (SDR family) member 2 \\
\hline 7909610 & ATF3 & 5.41 & Activating transcription factor 3 \\
\hline 8092578 & ETV5 & 5.26 & Ets variant 5 \\
\hline 8122724 & ULBP1 & 5.11 & UL16 binding protein 1 \\
\hline 7982868 & CHAC1 & 4.89 & ChaC, cation transport regulator homolog 1 (E. coli) \\
\hline 8160912 & C9orf131 & 4.82 & Chromosome 9 open reading frame 131 \\
\hline 7964460 & DDIT3 & 4.75 & DNA-damage-inducible transcript 3 \\
\hline 7963534 & KRT4 & -4.76 & Keratin 4 \\
\hline 7960919 & MFAP5 & -4.79 & Microfibrillar associated protein 5 \\
\hline 8040430 & VSNL1 & -5.25 & Visinin-like 1 \\
\hline 8015337 & KRT15 & -5.28 & Keratin 15 \\
\hline 8115623 & ATP10B & -5.36 & ATPase, class V, type 10B \\
\hline 8058857 & IGFBP5 & -5.41 & insulin-like growth factor binding protein 5 \\
\hline 8136336 & AKR1B10 & -5.48 & Aldo-keto reductase family 1 , member B 10 (aldose reductase) \\
\hline 8104758 & NPR3 & -5.78 & $\begin{array}{l}\text { Natriuretic peptide receptor } \mathrm{C} / \text { guanylate cyclase } \mathrm{C} \\
\text { (atrionatriuretic peptide receptor C) }\end{array}$ \\
\hline 8113709 & LOX & -6.35 & Lysyl oxidase \\
\hline 8171172 & MXRA5 & -7.98 & Matrix-remodelling associated 5 \\
\hline
\end{tabular}

A positive fold-change number indicates upregulation and a negative fold-change number indicates downregulation.

determined using a Qubit ${ }^{\mathrm{TM}}$ Fluorometer (Invitrogen; Thermo Fisher Scientific, Inc.) as described previously (32). For cDNA synthesis, the oligo (dT) Maxime RT premix kit according to the manufacturer's protocol (Intron Biotechnology, Inc., Seongnam, Korea) was used. The samples were hybridized to the Affymetrix GeneChip ${ }^{\circledR}$ Human Gene 1.0 ST array as described previously (Affymetrix, Inc., Santa Clara, CA, USA) (34), then the sample fluorescence was quantified by Asia BioInnovations Corporation (Taipei, Taiwan). The data was analyzed using Affymetrix ${ }^{\circledR}$ Expression Console ${ }^{\mathrm{TM}}$ software (Soft version 1.1.2; Affymetrix, Inc.) with default robust multiarray parameters. Following comparison of the control group with the CTD treated group, a 2-fold change in gene expression was used as the threshold to indicate a significant effect on expression (7-10).

Statistical analysis. Data are representative of three assays. Differences between control and CTD-treated groups were presented when they were $>2$-fold.

\section{Results}

CTD induces morphological changes in TSGH-8301 cells in vitro. Following treatment with $7.5 \mu \mathrm{M}$ CTD for 12, 24 and $48 \mathrm{~h}$, cells were examined and imaged using phase-contrast microscopy at a magnification of x200 (Fig. 1). Control cells without CTD treatment were incubated under identical conditions. The results indicated that CTD induced cell morphological changes, including cell size reduction, and decreased cell number in a dose-dependent manner.

CTD induces TSGH-8301 cell death in vitro. Following treatment with $7.5 \mu \mathrm{M}$ CTD for $48 \mathrm{~h}$, cells were examined using a TUNEL assay (Fig. 2). TUNEL-positive cells were observed in the CTD-treated group, but not in the control group. The number of apoptotic nuclei (green color) was higher in the CTD treated group compared with that of the control group (data not shown). These observations indicate that CTD induces apoptotic cell death in TSGH-8301 cells.

$C T D$ alters the expression of genes associated with the NKG2D-associated immune response in TSGH-8301 human bladder carcinoma cells. Following treatment with $7.5 \mu \mathrm{M}$ CTD for $48 \mathrm{~h}$, total RNA was extracted from TSGH-8301 cells for cDNA microarray analysis in order to examine changes in gene expression. The genes that were upregulated or downregulated, calculated from the microarray data, are displayed in in Tables I and II. A total of 269 genes were $>2$-fold upregulated and 286 genes were $>2$-fold downregulated (Table I). DNA-damage-inducible transcript 3 (DDIT3) was 4.75-fold upregulated, activating transcription factor 3 was 5.41-fold upregulated and dehydrogenase/reductase (SDR family) member 2 was 6.08-fold upregulated compared with the untreated control cells. Microfibrillar associated protein 5 was 4.79-fold downregulated, insulin-like growth factor binding protein 5 was 5.41-fold downregulated and matrix-remodeling 


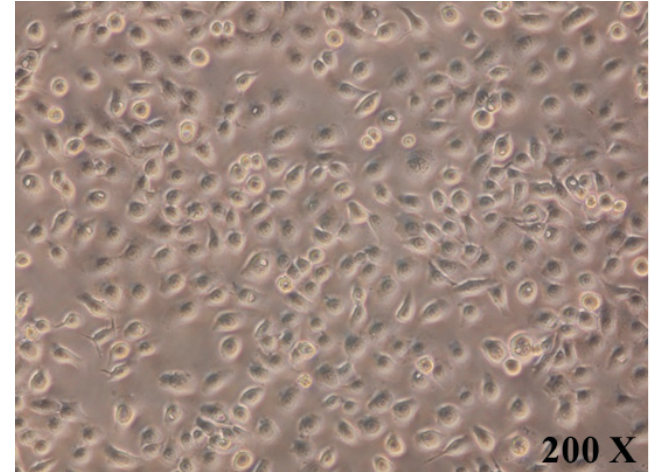

Control

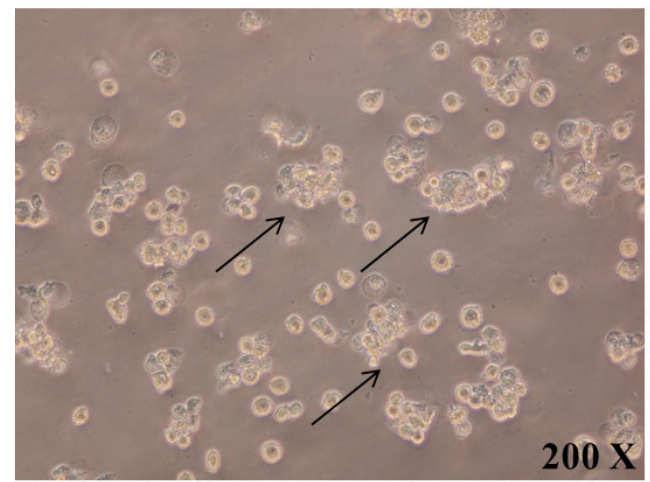

24 hour

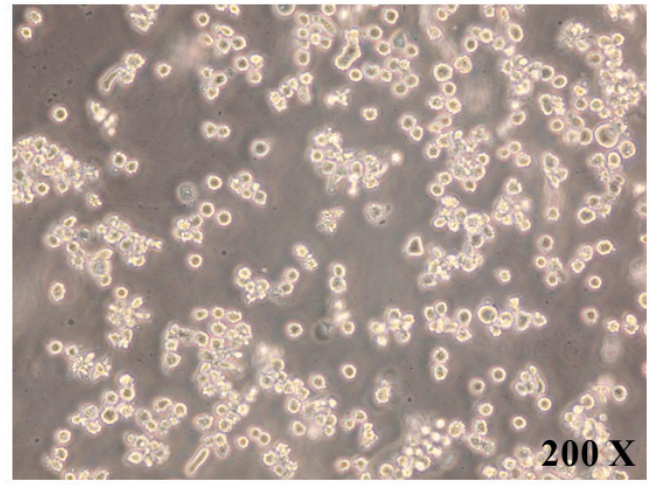

12 hour

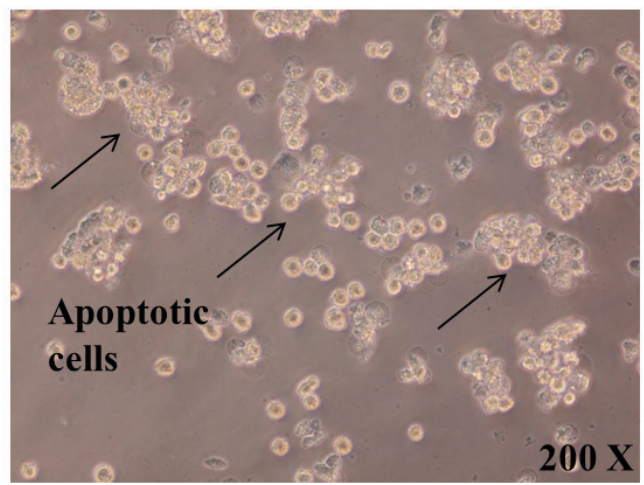

48 hour

Figure 1. Morphology of TSGH-8301 human bladder carcinoma cells following treatment with $7.5 \mu \mathrm{M}$ cantharidin for 12,24 and 48 h. Arrows indicate apoptotic cells. Cell morphology was examined using a phase-contrast microscope (magnification, x200).

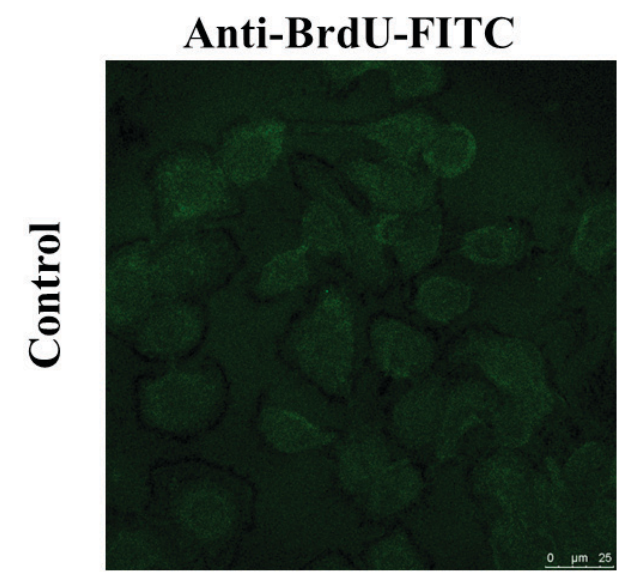

Anti-BrdU-FITC

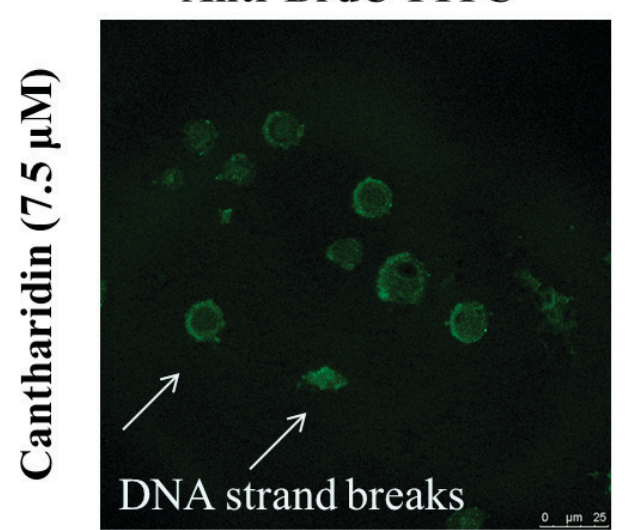

PI

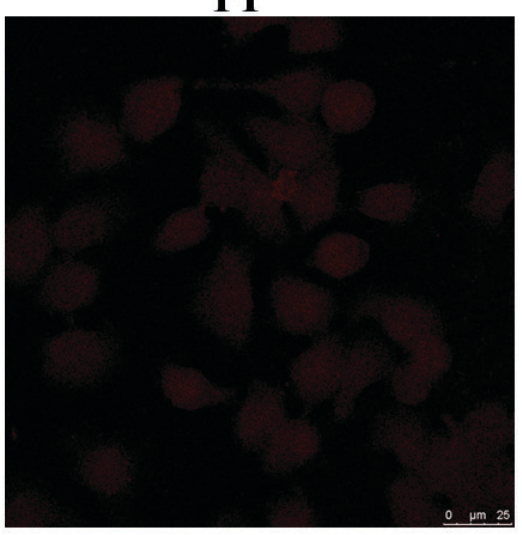

PI

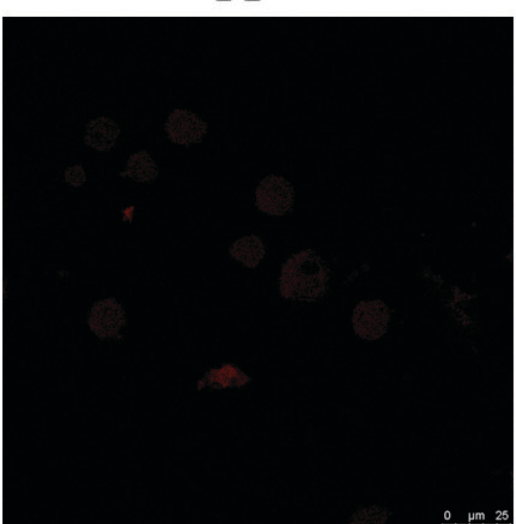

Merge

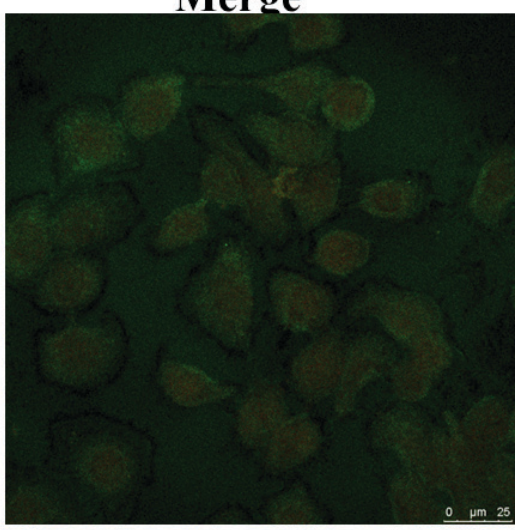

Merge

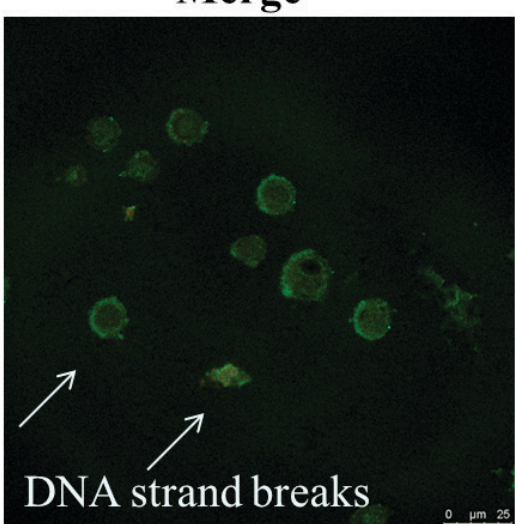

Figure 2. Cantharidin increases DNA fragmentation-associated BrdU-FITC signaling in TSGH-8301 cells compared with untreated control cells. BrdU, bromodeoxyuridine; FITC, fluorescein isothiocyanate; PI, propidium iodide. 


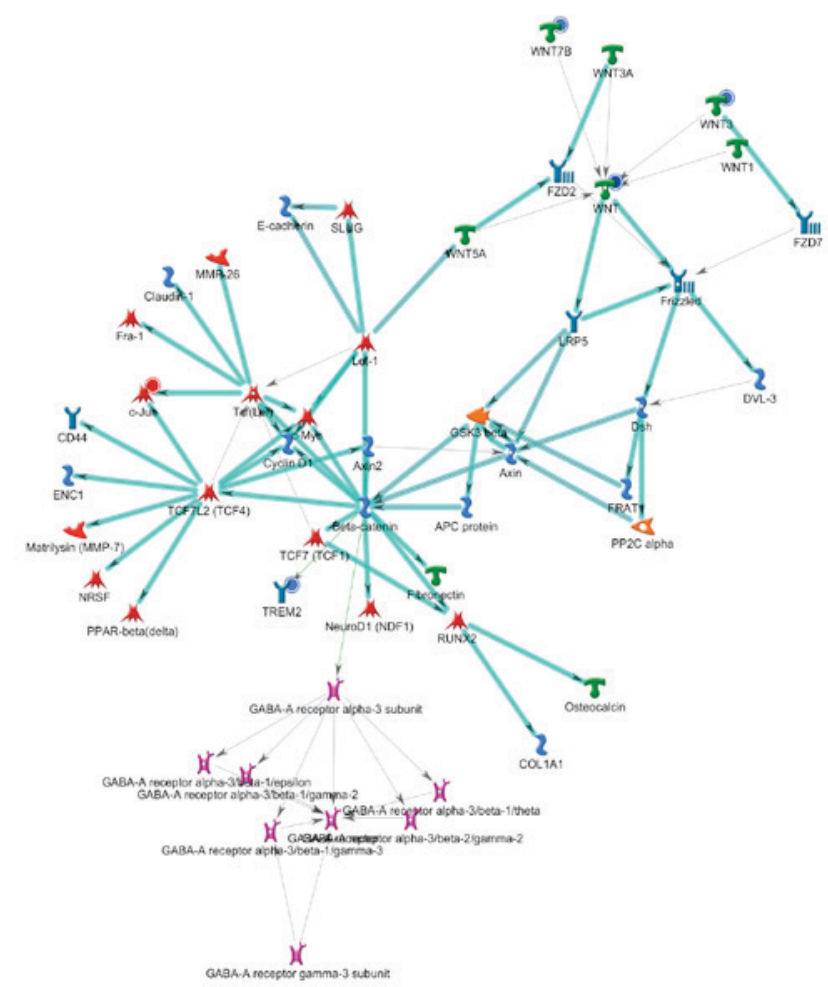

Figure 3. Top scored (by the number of pathways) Analyze Network network. Thick cyan lines indicate the fragments of canonical pathways. Upregulated genes are marked with red circles and downregulated genes with blue circles.

associated 5 (MXRA5) was 7.98-fold downregulated compared with the untreated control cells (Table II).

CTD-treatment alters signaling pathways in TSGH-8301 cells. In order to investigate the molecular signaling pathways associated with the genes whose expression was altered by CTD, a GeneGo analysis was performed. The analysis from GeneGo for immune responses for human NKG2D type II integral membrane protein signaling were the top, second and third highest scored Analyze Network (AN) networks (data not shown), by the number of pathways (Figs. 3-5). Therefore, NKG2D was selected as there were significant effects following CTD treatment compared with that of control.

\section{Discussion}

The results from the present study demonstrated that CTD induces cell morphological changes and apoptosis, as revealed using phase-contrast microscopy and a TUNEL assay, respectively, in TSGH-8301 human bladder carcinoma cells. Tumor cell lines are invaluable research tools that are able to be experimentally manipulated (35). The TSGH-8301 cells are derived from a well-differentiated human transitional cell carcinoma of the urinary bladder (36). In addition, CTD treatment resulted in the upregulation and downregulation of a number of immune response-associated genes. Numerous studies have demonstrated that CTD induces a cytotoxic effect in a number of human cancer cell lines. For example, CTD affects gene expression in human lung cancer NCI-H460 cells (32) Additionally, CTD induces cell apoptosis through mitochondrial-dependent signaling pathways (25), and inhibits

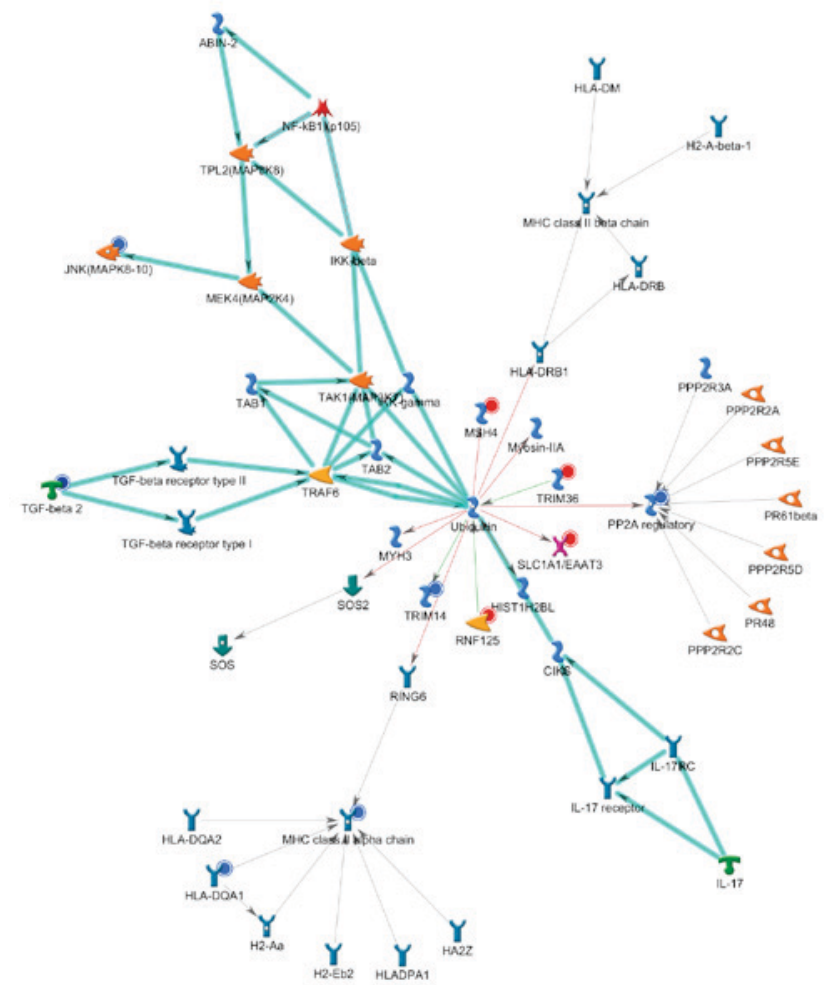

Figure 4. Second highest scored (by the number of pathways) Analyze Network network. Thick cyan lines indicate the fragments of canonical pathways. Upregulated genes are marked with red circles and downregulated genes with blue circles.

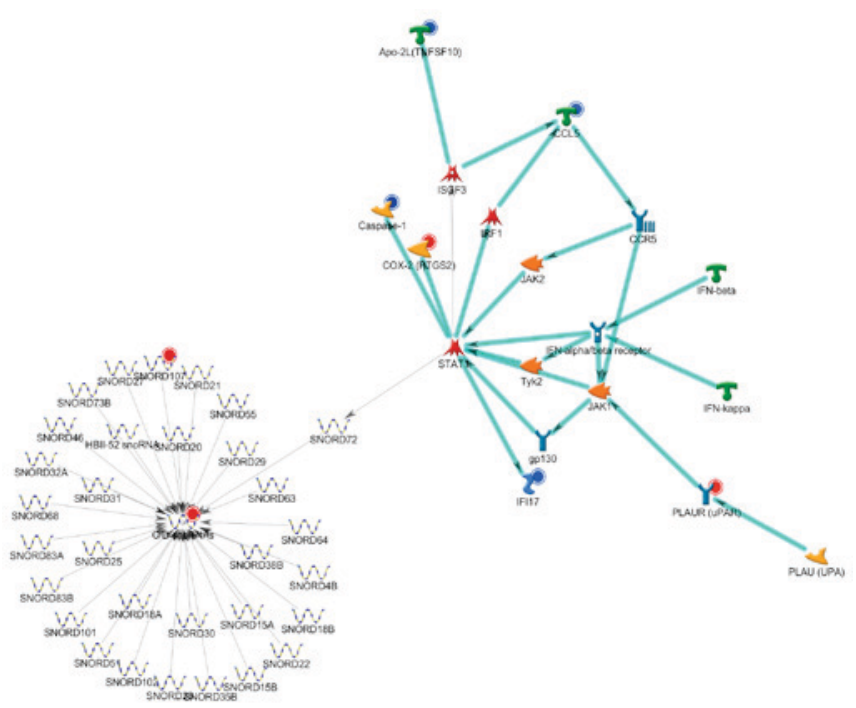

Figure 5. Third highest scored (by the number of pathways) Analyze Network network. Thick cyan lines indicate the fragments of canonical pathways. Upregulated genes are marked with red circles and downregulated genes with blue circles.

cell migration and invasion through the inhibition of the matrix metalloproteinase-2/-9 signaling pathway in human bladder cancer TSGH-8301 cells (37). Other studies in human bladder cancer T24 cells have also demonstrated that CTD induces apoptosis through the calcium/PKC-regulated endoplasmic reticulum stress signaling pathway (38). However, to the best of our knowledge no studies have demonstrated the effect of 
CTD on gene expression in human bladder cancer cells. Thus, in the present study, the effect of CTD on gene expression in human bladder cancer TSGH-8301 cells was investigated in vitro.

In the present study, human bladder cancer TSGH-8301 cells were treated with $7.5 \mu \mathrm{M}$ CTD, followed by analysis of cell morphology and apoptotic cell death using phase-contrast microscopy and the TUNEL assay. The results demonstrated that CTD induces apoptotic cell death and morphological changes in human bladder cancer TSGH-8301 cells. Compared with the control group, cells treated with CTD exhibited increased DNA strand breaks, as visualized using an ApoBrdU DNA Fragmentation Assay kit. This result indicates that CTD induces apoptotic cell death via DNA fragmentation in TSGH-8301 cells.

The changes in cell morphology observed in the present study as a result of CTD treatment were dose-dependent. Additionally, CTD induced apoptotic cell death in a dose-dependent manner, as indicated by TUNEL staining.

A previous study demonstrated that CTD affects gene expression in the human lung cancer NCI-H460 cell line (32). Additionally, a recent study identified, using next generation sequencing, that human bladder cancer has numerous gene alterations compared with normal tissue, with most predicted to be loss-of-function mutations; however, evaluating the functional impact of each genetic alteration is impractical (39). The present study, to the best of our knowledge, is the first to demonstrate the effects of CTD on gene expression in human bladder TSGH-8301 cancer cells. Thus, the results from the present study offer an insight into CTD-induced gene expression changes in bladder cancer cells, which will aid in the identification of potential biomarkers for patients with bladder cancer that require targeted therapy.

A number of studies have shown that the matrix proteins, stromal cells and associated secreted molecules that comprise the tumor microenvironment serve a role in mediating responses to cancer drugs (40-42). Therefore, in the present study, changes in gene expression in TSGH-8301 cells following exposure to CTD for $24 \mathrm{~h}$ were analyzed using a cDNA microarray. CTD treatment resulted in an $>2$-fold upregulation of 269 genes and an >2-fold downregulation of 286 genes in TSGH-8301 cells. DDIT3, which is associated with DNA damage, was upregulated 4.75-fold and MXRA5, which is associated with cell migration and invasion, was downregulated 7.98-fold. In order to further investigate the genes whose expression was altered in response to CTD, and their associated molecular signaling pathways, a GeneGo process network analysis was performed. This suggested that CTD treatment affects a number of associated signaling pathways, including the NKG2D signaling pathway, in TSGH-8301 cells.

In conclusion, the data from the present study indicates that CTD induces cytotoxic effects in TSGH-8301 cells, based on the observed decrease in the number of cells and increase in apoptotic cell death in CTD-treated cells compared with control untreated cells. Additionally, CTD treatment resulted in the upregulation or downregulation of numerous genes that are associated with a number of immune response-associated molecular signaling pathways. These findings may aid in future research into the molecular targets of CTD.

\section{Acknowledgements}

The present study was supported by the China Medical University (Taichung, Taiwan; grant no. CMU103-ASIA-01). Experiments and data analysis were performed in part at the Medical Research Core Facilities Center of the Office of Research \& Development at China Medical University.

\section{References}

1. Knowles MA: The genetics of transitional cell carcinoma: Progress and potential clinical application. BJU Int 84: 412-427, 1999.

2. Pudasaini S, Subedi N, Prasad KB, Rauniyar SK, Joshi BR and Bhomi KK: Cystoscopic bladder biopsies: A histopathological study. Nepal Med Coll J 16: 9-12, 2014.

3. Ferlay J, Soerjomataram I, Dikshit R, Eser S, Mathers C, Rebelo M, Parkin DM, Forman D and Bray F: Cancer incidence and mortality worldwide: Sources, methods and major patterns in GLOBOCAN 2012. Int J Cancer 136: E359-E386, 2015.

4. Jemal A, Bray F, Center MM, Ferlay J, Ward E and Forman D: Global cancer statistics. CA Cancer J Clin 61: 69-90, 2011.

5. Parkin DM: The global burden of urinary bladder cancer. Scand J Urol Nephrol Suppl 12-20, 2008.

6. Boffetta P: Tobacco smoking and risk of bladder cancer. Scand J Urol Nephrol Suppl 45-54, 2008

7. Prasad SM, Decastro GJ and Steinberg GD; Medscape: Urothelial carcinoma of the bladder: Definition, treatment and future efforts. Nat Rev Urol 8: 631-642, 2011.

8. Ministry of Health and Welfare (Taiwan): Taiwan Statistics of causes of death 2006. Ministry of Health and Welfare (Taiwan), Taipei City, 2006.

9. Moed L, Shwayder TA and Chang MW: Cantharidin revisited: A blistering defense of an ancient medicine. Arch Dermatol 137: 1357-1360, 2001.

10. Wang GS: Medical uses of mylabris in ancient China and recent studies. J Ethnopharmacol 26: 147-162, 1989.

11. Karras DJ, Farrell SE, Harrigan RA, Henretig FM and Gealt L. Poisoning from 'Spanish fly' (cantharidin). Am J Emerg Med 14: 478-483, 1996.

12. Swingle M, Ni L and Honkanen RE: Small-molecule inhibitors of ser/thr protein phosphatases: Specificity, use and common forms of abuse. Methods Mol Biol 365: 23-38, 2007.

13. Li W, Xie L, Chen Z, Zhu Y, Sun Y, Miao Y, Xu Z and Han X Cantharidin, a potent and selective PP2A inhibitor, induces an oxidative stress-independent growth inhibition of pancreatic cancer cells through $\mathrm{G} 2 / \mathrm{M}$ cell-cycle arrest and apoptosis. Cancer Sci 101: 1226-1233, 2010.

14. Li W, Chen Z, Gong FR, Zong Y, Chen K, Li DM, Yin H, Duan WM, Miao Y, Tao M et al: Growth of the pancreatic cancer cell line PANC-1 is inhibited by protein phosphatase $2 \mathrm{~A}$ inhibitors through overactivation of the c-Jun N-terminal kinase pathway. Eur J Cancer 47: 2654-2664, 2011.

15. Li W, Chen Z, Zong Y, Gong F, Zhu Y, Zhu Y, Lv J, Zhang J, Xie L, Sun Y, et al: PP2A inhibitors induce apoptosis in pancreatic cancer cell line PANC-1 through persistent phosphorylation of IKK $\alpha$ and sustained activation of the NF- $\mathrm{B}$ p pathway. Cancer Lett 304: 117-127, 2011.

16. Huh JE, Kang KS, Chae C, Kim HM, Ahn KS and Kim SH: Roles of $\mathrm{p} 38$ and JNK mitogen-activated protein kinase pathways during cantharidin-induced apoptosis in U937 cells. Biochem Pharmacol 67: 1811-1818, 2004.

17. Chang C, Zhu YQ, Mei JJ, Liu SQ and Luo J: Involvement of mitochondrial pathway in NCTD-induced cytotoxicity in human hepG2 cells. J Exp Clin Cancer Res 29: 145, 2010.

18. Huang WW, Ko SW, Tsai HY, Chung JG, Chiang JH, Chen KT, Chen YC, Chen HY, Chen YF and Yang JS: Cantharidin induces G2/M phase arrest and apoptosis in human colorectal cancer colo 205 cells through inhibition of CDK1 activity and caspase-dependent signaling pathways. Int J Oncol 38: 1067-1073, 2011.

19. Zhang WD, Zhao HR, Yan Y, Wang XH, Zong ZH and Liu Y: Apoptosis induced by cantharidin in human pulmonary carcinoma cells A549 and its molecular mechanisms. Zhonghua Zhong Liu Za Zhi 27: 330-334, 2005 (In Chinese).

20. Huan SK, Lee HH, Liu DZ, Wu CC and Wang CC: Cantharidin-induced cytotoxicity and cyclooxygenase 2 expression in human bladder carcinoma cell line. Toxicology 223: 136-143, 2006. 
21. Li W, Li DM, Chen K, Chen Z, Zong Y, Yin H, Xu ZK, Zhu Y, Gong FR and Tao M: Development of a gene therapy strategy to target hepatocellular carcinoma based inhibition of protein phosphatase $2 \mathrm{~A}$ using the $\alpha$-fetoprotein promoter enhancer and pgk promoter: An in vitro and in vivo study. BMC Cancer 12: 547, 2012.

22. Xie X, Wu MY, Shou LM, Chen LP, Gong FR, Chen K, Li DM, Duan WM, Xie YF, Mao YX, et al: Tamoxifen enhances the anticancer effect of cantharidin and norcantharidin in pancreatic cancer cell lines through inhibition of the protein kinase $\mathrm{C}$ signaling pathway. Oncol Lett 9: 837-844, 2015.

23. Hsiao YP, Tsai CH, Wu PP, Hsu SC, Liu HC, Huang YP, Yang JH and Chung JG: Cantharidin induces G2/M phase arrest by inhibition of Cdc25c and Cyclin A and triggers apoptosis through reactive oxygen species and the mitochondriadependent pathways of A375.S2 human melanoma cells. Int J Oncol 45: 2393-2402, 2014.

24. Hsia TC, Yu CC, Hsu SC, Tang NY, Lu HF, Huang YP, Wu SH, Lin JG and Chung JG: Cantharidin induces apoptosis of H460 human lung cancer cells through mitochondria-dependent pathways. Int J Oncol 45: 245-254, 2014

25. Kuo JH, Chu YL, Yang JS, Lin JP, Lai KC, Kuo HM, Hsia TC and Chung JG: Cantharidin induces apoptosis in human bladder cancer TSGH 8301 cells through mitochondria-dependent signal pathways. Int J Oncol 37: 1243-1250, 2010

26. Evans HJ and Prosser J: Tumor-suppressor genes: Cardinal factors in inherited predisposition to human cancers. Environ Health Perspect 98: 25-37, 1992.

27. Tang C, Guo J, Chen H, Yao CJ, Zhuang DX, Wang Y, Tang WJ, Ren G, Yao Y, Wu JS, et al: Gene mutation profiling of primary glioblastoma through multiple tumor biopsy guided by 1H-magnetic resonance spectroscopy. Int J Clin Exp Pathol 8: $5327-5335,2015$

28. Heneghan HM, Miller N and Kerin MJ: MiRNAs as biomarkers and therapeutic targets in cancer. Curr Opin Pharmacol 10 543-550, 2010

29. Osborne C, Wilson P and Tripathy D: Oncogenes and tumor suppressor genes in breast cancer: Potential diagnostic and therapeutic applications. Oncologist 9: 361-377, 2004.

30. Ai X, Jia ZM, Wang J, Di GP, Zhang XU, Sun F, Zang T and Liao X: Bioinformatics analysis of the target gene of fibroblast growth factor receptor 3 in bladder cancer and associated molecular mechanisms. Oncol Lett 10: 543-549, 2015.

31. Spiegelberg C, Giedl J, Gaisa NT, Rogler A, Riener MO, Filbeck T, Burger M, Ruemmele P, Hartmann A and Stoehr R: Frequency of activating mutations in FGFR 2 exon 7 in bladder tumors from patients with early-onset and regular-onset disease. Int J Clin Exp Pathol 7: 1708-1713, 2014.

32. Hsia TC, Yu CC, Hsu SC, Tang NY, Lu HF, Yu CS, Wu SH, Lin JG and Chung JG: cDNA microarray analysis of the effect of cantharidin on DNA damage, cell cycle and apoptosis-associated gene expression in NCI-H460 human lung cancer cells in vitro. Mol Med Rep 12: 1030-1042, 2015.
33. Lu CC, Yang JS, Chiang JH, Hour MJ, Lin KL, Lee TH and Chung JG: Cell death caused by quinazolinone HMJ-38 challenge in oral carcinoma CAL 27 cells: Dissections of endoplasmic reticulum stress, mitochondrial dysfunction and tumor xenografts. Biochim Biophys Acta 1840: 2310-2320, 2014.

34. Chou YC, Chang MY, Wang MJ, Liu HC, Chang SJ, Harnod T, Hung CH, Lee HT, Shen CC and Chung JG: Phenethyl isothiocyanate alters the gene expression and the levels of protein associated with cell cycle regulation in human glioblastoma GBM 8401 cells. Environ Toxicol 32: 176-187, 2017.

35. Barretina J, Caponigro G, Stransky N, Venkatesan K, Margolin AA, Kim S, Wilson CJ, Lehár J, Kryukov GV, Sonkin D, et al: The Cancer Cell Line Encyclopedia enables predictive modelling of anticancer drug sensitivity. Nature 483: 603-607, 2012.

36. Yeh MY, Yu DS, Chen SC, Lin MS, Chang SY, Ma CP and Han SH: Establishment and characterization of a human urinary bladder carcinoma cell line (TSGH-8301). J Surg Oncol 37: 177-184, 1988

37. Huang YP, Ni CH, Lu CC, Chiang JH, Yang JS, Ko YC, Lin JP, Kuo JH, Chang SJ and Chung JG: Suppressions of Migration and Invasion by Cantharidin in TSGH-8301 human bladder carcinoma cells through the inhibitions of matrix metalloproteinase-2/-9 signaling. Evid Based Complement Alternat Med 2013: 190281, 2013.

38. Su CC, Liu SH, Lee KI, Huang KT, Lu TH, Fang KM, Wu CC, Yen CC, Lai CH, Su YC and Huang CF: Cantharidin induces apoptosis through the calcium/PKC-regulated endoplasmic reticulum stress pathway in human bladder cancer cells. Am J Chin Med 43: 581-600, 2015.

39. Hensel J, Duex JE, Owens C, Dancik GM, Edwards MG, Frierson HF and Theodorescu D: Patient mutation directed shRNA screen uncovers novel bladder tumor growth suppressors. Mol Cancer Res 13: 1306-1315, 2015.

40. Ayala F, Dewar R, Kieran M and Kalluri R: Contribution of bone microenvironment to leukemogenesis and leukemia progression. Leukemia 23: 2233-2241, 2009.

41. Straussman R, Morikawa T, Shee K, Barzily-Rokni M, Qian ZR, Du J, Davis A, Mongare MM, Gould J, Frederick DT, et al: Tumour micro-environment elicits innate resistance to RAF inhibitors through HGF secretion. Nature 487: 500-504, 2012.

42. Wilson TR, Fridlyand J, Yan Y, Penuel E, Burton L, Chan E, Peng J, Lin E, Wang Y, Sosman J, et al: Widespread potential for growth-factor-driven resistance to anticancer kinase inhibitors. Nature 487: 505-509, 2012. 